International Journal of Advanced Trends in Computer Science and Engineering

Available Online at http://www.warse.org/IJATCSE/static/pdf/file/ijatcse3891.32020.pdf

https://doi.org/10.30534/ijatcse/2020/3891.32020

\title{
A Review on Risk Assessment Using Risk Prediction Technique in Campus Network
}

\author{
Norkhushaini Awang ${ }^{1}$, Ganthan A/L Narayana Samy², Noor Hafizah Hassan ${ }^{3}$, \\ Pritheega A/P Magalingam ${ }^{4}$, Nurazean Maarop ${ }^{5}$, Sundresan A/L Perumal ${ }^{6}$ \\ ${ }^{1}$ Advanced Informatics School, Universiti Teknologi Malaysia, Jalan Sultan Yahya Petra, 54100 Kuala Lumpur, \\ Malaysia., shaini@tmsk.uitm.edu.my \\ ${ }^{2}$ Advanced Informatics School, Universiti Teknologi Malaysia, Jalan Sultan Yahya Petra, 54100 Kuala Lumpur, \\ Malaysia., ganthan.kl@utm.my \\ ${ }^{3}$ Advanced Informatics School, Universiti Teknologi Malaysia, Jalan Sultan Yahya Petra, 54100 Kuala Lumpur, \\ Malaysia., noorhafizah.kl@utm.my \\ ${ }^{4}$ Advanced Informatics School, Universiti Teknologi Malaysia, Jalan Sultan Yahya Petra, 54100 Kuala Lumpur, \\ Malaysia., mpritheega.kl@utm.my \\ ${ }^{5}$ Advanced Informatics School, Universiti Teknologi Malaysia, Jalan Sultan Yahya Petra, 54100 Kuala Lumpur, \\ Malaysia., nurazean.kl@utm.my \\ ${ }^{6}$ Faculty of Science and Technology, Universiti Sains Islam Malaysia, Bandar Baru Nilai, 71800, Negeri \\ Sembilan, Malaysia., sundresan.p@usim.edu.my
}

\begin{abstract}
Risk assessment is an important part of a risk management process to secure information systems. The risk assessment activities helped organizations determine the acceptable level of risk. Understanding and assessing risk is an important process to improve information security in making decisions. Risk prediction is an important part of information security system. In order to security operation center understand their environment, risk prediction technique helped them to create a holistic understanding of the networks, systems, services and applications they are responsible for monitoring. In this research paper, we discussed past related research in doing a risk prediction in conducting a risk assessment activity at the campus network. We have selected 5 key databases in computer science area. We have refined the searching based on subject area, types of document, publication title, index terms, sub-keyword and source title. In doing the screening process, we exclude articles that did not meet research selection criteria based on keyword searching in the papers. From the comprehensive literature search databases searching, we have selected 15 articles related to subject risk prediction conducted in campus network.
\end{abstract}

Key words: Risk assessment; prediction technique; comprehensive literature search; campus network.

\section{INTRODUCTION}

A discussion from [1] mention that cyber-attacks are increasing and becoming a growing concern for organizations and governments sectors. They also report that network infrastructure severely impacts service uptime, data integrity, and compliance that require organizations implement countermeasure steps to deal with these security concerns. The protection of network system has become a challenge to the organizations because of attackers are using advance methods to penetrate the databases although network administrator secure the connection to login to databases [2]. An effective security strategy is by conducting a risk assessment in the organizations. According to [3] the process of assessing information systems security handled the uncertainty of risk assessment by identifying the information security assets that are vulnerable to threats. Discussion from [4] in their paper, stated that information security risk assessment and management methods provide an effective way to detect actual threats and select suitable security controls for their organization. A discussion about threats in the university environment also been mention by [5] stated that two primary threats in the university network are from insider users and cyber threat. To manage these threats are complicated because of information media and social media. All community members in university are responsible in managing the campus network. Authors also explained that university campuses are where the community learn, work and their hostel. Many on-campus buildings are open 24 hours a day and are utilized by faculty, staff and students, as well as the public. Community in the university are communicate through common email systems, social media, and other communication systems. As such, university administrators are often met with challenges in dealing with threats. It is important to conduct a risk assessment in the university information system to give the preparedness before risk happens in the university. In this research we reviewed implementation of risk prediction technique in campus network. 


\section{RELATED WORK}

Risk assessment implementation in campus network is critical as the resources are important to university productivity. Inadequate information technology security risk assessment may result in compromised confidentiality, integrity, and availability of the information system due to unauthorized access. To ensure that information system protected, university network administrator should implement information security risk assessment practices [6]. In the same report also mentioned that risk assessment is a crucial task for minimization of the potential risks. This activity also help administrator to determine the value of the various types of data stored across the organization. Discussion from [7] emphasized that organizations ongoing activities on security solutions is conducted to integrate with existing guidelines, best practices, security standards and existing solutions. However, while doing the risk assessment, organizations are nonconcrete in giving the suggestions for risk mitigation and decision making. Mostly of the decision is based on subjective perceptions, instead of objective evaluation.

Information security administrator deal with challenging task of assessing the information security risks. According to [8] clarified that lack of complete information about the vulnerabilities in the system leads to the problem of information ambiguity between the security administrators. This leads to difficulty in assessing the severity of vulnerabilities and estimation of the impact of an attack. It has been claimed by [9] where the challenges with extensive attacks and needs for the systems to create security plan and risk assessment by assigning the information's and resources about the system.

Most of the assessment in university is a qualitative analysis, lack of quantitative, systematic and standardized risk analysis [10]. From the studied on risk assessment in universities, authors emphasized that university management only focus on network security rather than information security [11]. There are lack of standard framework for information security assessment in University Information System (UIS). The importance of risk assessment in UIS also been mention by [12]. Authors clarified that it is important to conduct risk analysis to help in making a decision to manage UIS. From the discussion, [13] also mention that in the large university campus network, there is needed to improve risk position and security countermeasure. Admin are required to identify critical threats and conducting assessment of vulnerabilities to measure risk level from continuous network monitoring of university campus network. Prediction technique one of the proposed approach to identify a risk level from the statistical analysis.

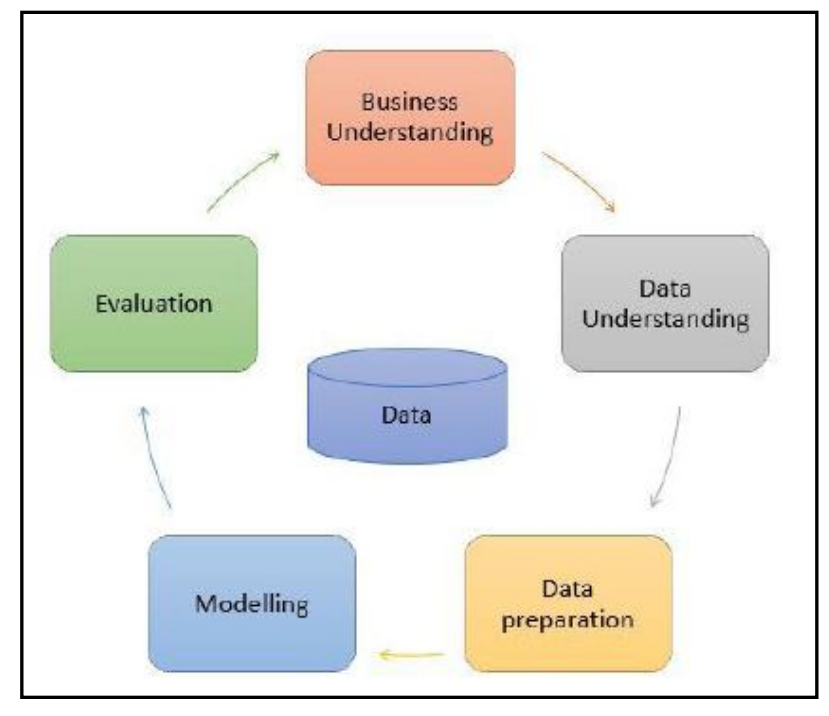

Figure 1: Cross-Industry Process For Data Mining (CRISP-DM) [14]

Risk prediction technique is an important part of information security system to help in doing risk assessment process. Data mining process as in Figure 1 show how industry do the data mining steps before doing the risk prediction analysis. Previous research claimed that information security system needs an effective prediction method [15]. Authors also mention that the information security risk assessment process and combination of assets, threat, vulnerability and safety control measures, to strengthen the correlation among these factors and make the prediction results more objective for the target assets. The combination of domestic and foreign information security standards with the actual situation of evaluation object is necessary to set up appropriate risk prediction system. Other researcher [16] mention that predictive data analytics is the architecture models that make predictions based on patterns mined from historical data. In conducting a prediction risk assessment, [17] stated that data analytics is a method of exploring massive sets of data to take out patterns which are hidden and previously unknown relationships and knowledge detection to help the better understanding. In this research paper, researchers review on data analytics approach as doing the risk prediction. In doing data analysis, we proposed to use an iterative process called epicycles of analysis as in Figure 2. The first step in this process, we have to develop expectation by conducted deliberately thinking about what we expect before start doing the experiment such as inspect our data, perform a procedure, and enter a command. After we have some expectations about what the result will be, next step we perform the iterative operation. In our research, we proposed to have data from firewall devices which located in the campus network. 


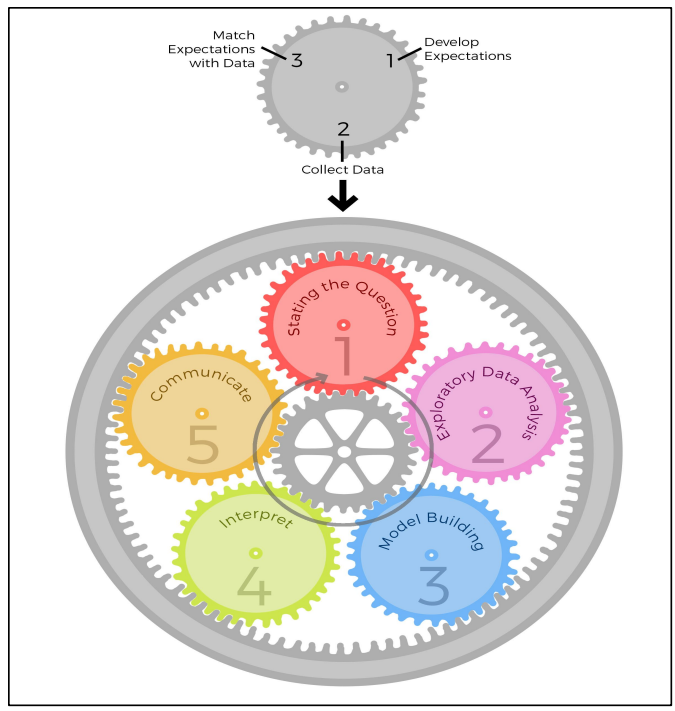

Figure 2: Iterative Process of Epicycles [18]

An epicycle of analysis approach is an iterative process from small circle to a larger circle. Some data analyses appear to be fixed and linear [18]. However, these algorithms are final data analysis products that have emerged from the non-linear work of developing.

More discussion on the importance of risk prediction also mention by [19] stated that the process of choose, select and also customize a prediction model for an intended purpose, should be carried out wisely using appropriate metrics, tolerance, and criteria. They also elaborate that by conducting risk prediction increased appropriate decision-making. Other researchers [20] explained that by using prediction system reduced human wrong judgement and cost effective. They claimed that prediction technique helped them to decrease the cost concurrently as much as $30 \%$ of overall spending. Research by [21] claimed that conventional statistical metrics which used primary data generates simple descriptive analysis where often provide insufficient knowledge for decision making. By using data analytics approach, it's provided capability to find hidden pattern from the secondary data in large databases and create prediction for desired output and has become a popular approach to develop risk prediction model. All the researches show how risk prediction is important in doing a reliable decision making. Figure 3 illustrate the process of doing predictive analysis.

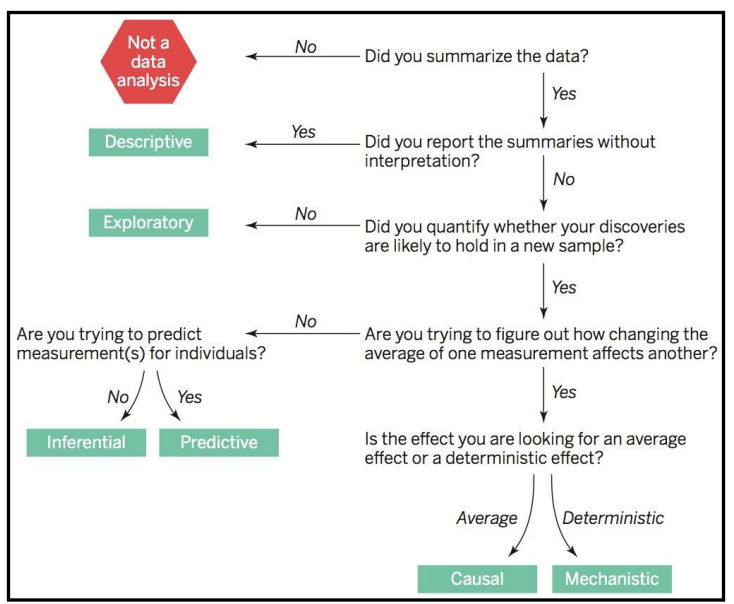

Figure 3: Descriptive and Predictive Modelling [22]

From Figure 3 we can described the differences between predictive analysis and descriptive analysis. Predictive analysis helps an organization to identify what will happen next by predicting future based on present data available nevertheless descriptive analysis helps an organization to identify what has happened in the past and provide the past analytics using in warehouse data.

\section{METHODOLOGY}

In this sub-topic, we discussed about previous study on predictive analysis in risk assessment. As we mentioned in previous discussion, the process of create, test and validate are steps to predict the suitable prediction model by looking at the probability of an outcome. A discussion further explained about using data mining in doing a prediction. Later, we conducted a comprehensive literature search in finding the current research trend about using prediction technique in managing campus network. We focus a study on implementing predictive analysis in analysing cybersecurity threats.

\subsection{Data Mining Algorithm in Prediction Technique}

Prediction technique using data mining is a process finding out the knowledge or pattern from the large data. The era of data warehouses where the complexity and variety of sources motivate data scientist implemented data mining to analysis the massive data. Refer to a study from [21] stated that data mining techniques have the capability to find hidden pattern from the secondary data in large databases and create prediction for desired output. This approach helps to develop risk prediction model. Predictive analysis is a branch of data mining in doing the future probabilities. By using structured and unstructured data, data mining helps the business users to create predictive intelligence by looking at the pattern behavioral of the data and their relationship. 
Recently, university data warehouse is exposed to security threats where have prompted university management calls for improved risk monitoring and modelling. According to [23] explained that by developing statistical and data mining techniques, it helps network admin directive to analyze and displayed the data in a coherent and structure way. Authors also stated that it is important conducting proper risk assessment using suitable methodology which looked for potential vulnerable points of network security threats. By using predictive analysis, its help management in detecting network fraud, optimizing marketing by studying customer behavioral, improving current operation practice and also help management in reducing their own risk. There are a few data mining algorithm in predictive modelling which are logistic regression, time series analysis, decision tree and neural network. From a study, [24] mention about the development of risk prediction system for predicting the risk in real-time. This system helped them from being mishandled the outcome. Their research study focuses on classification algorithm for detecting a risk. The model is used to forecast an outcome at desired future state or time based refer from data inputs. Analyzing from data inputs is much faster after conducting sampling activity before select the right model.

Figure 4 show steps in data mining, start from business understanding, data understanding, data preparation, modelling, evaluation and deployment. In data modelling step, we can use different predictive analytic techniques to train the algorithm to learn from the historical data. The predictive model should be able to identify trends and user behaviors and correlate to the data into successful predictions.

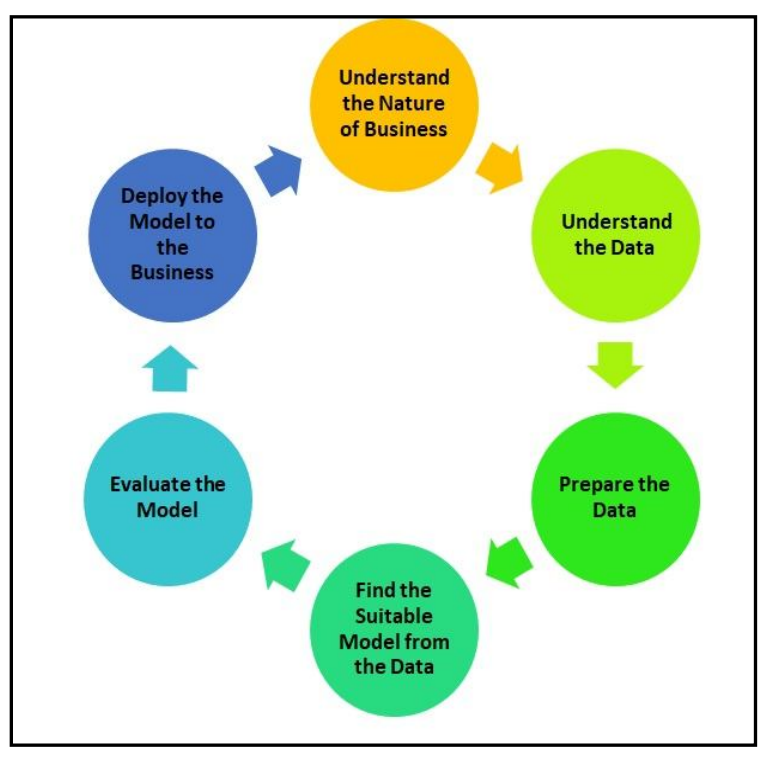

Figure 4: Steps in Data Mining
Another research from [25] explained that data mining was used to study possible relations between the risk levels of chain analysis and how data mining techniques helped them conduct risk mitigation strategies. Another discussion from [26] also explained how data mining help their studied in infrastructure environment. Data mining helped them to predict information security measurement and visualise based on data from practical experience. By conducting predictive analysis, it allows business become proactive to make an assumption based on the data that they have.

\subsection{Comprehensive Literature Search}

We have conducted a comprehensive literature search in filtering current research pattern focusing on keywords: (risk AND prediction AND education OR campus OR education AND network). The process of searching was conducted using top 5 computer science research databases which are: Web Of Science (WoS), Scopus, IEEE Xplore, SpringerLink and ACM Digital Library. The searching looked from year 2016 until current publication.

In filtering the subject, we excluded if the topic of discussion is unrelated to risk prediction in university network. For example, studies that involved management risk, medical risk, engineering risk, financial risk and other risk area were excluded from the literature review. Furthermore, studies that does not discussed about data mining techniques were also excluded. For this purpose, articles published from 2016-2019 are taken into consideration during the search process. Figure 5 below shows the result from the systematic database filtering taken from 5 selected databases.

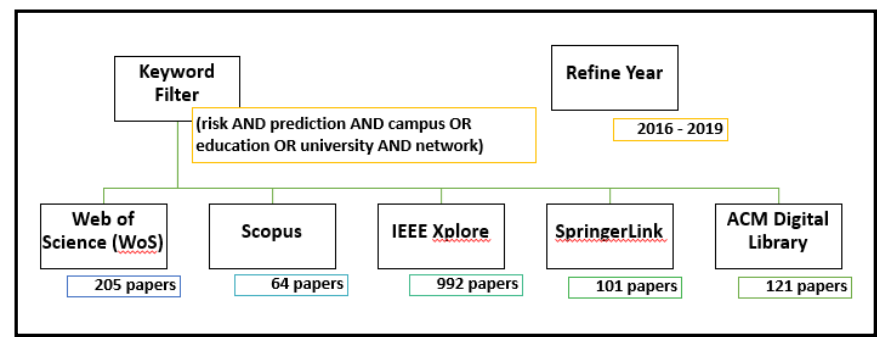

Figure 5: Summary from Database Filtering

From Table I below, we show keyword syntax that we used to do the filtering. From 5 key databases in computer science, we refined the searching based on subject area, types of document, publication title, index terms, sub-keyword and source title. There are some duplication papers from 5 databases that we used and checked and removed leaving only 433 papers. The screening process continued by excluding articles that did not meet selection criteria based on abstract review resulting in 73 selected articles. Finally, 15 selected articles were used for this review paper after excluded because the articles did not contain adequate discussion on the risk prediction in university network. 
Norkhushaini Awang et al., International Journal of Advanced Trends in Computer Science and Engineering, 9(1.3), 2020,251 - 257

Table 1: Keyword Syntax for Database Filtering

\begin{tabular}{|c|c|}
\hline $\begin{array}{l}\text { DATABASE } \\
\text { NAME }\end{array}$ & KEYWORD SYNTAX \\
\hline $\begin{array}{l}\text { Web of Science } \\
\text { (WoS) }\end{array}$ & $\begin{array}{l}\text { TOP IC: (risk) AND TOP IC: (prediction) OR } \\
\text { TOP IC: (university) OR TOP IC: (campus) OR } \\
\text { TOPIC : (education) AND TOP IC : (network) } \\
\\
\text { Refined by: WEB OF SCIENCE CATEGORIES: } \\
\text { ( COMPUTER SCIENCE INFORMATION } \\
\text { SYSTEMS OR COMPUTER SCIENCE } \\
\text { SOFTWARE ENGINEERING OR COMPUTER } \\
\text { SCIENCE THEORY METHODS OR } \\
\text { ENGINEERING MULTIDISCIPLINARY OR } \\
\text { COMPUTER SCIENCE INTERDISCIPLINARY } \\
\text { APPLICATIONS OR COMPUTER SCIENCE } \\
\text { ARTIFICIAL INTELLIGENCE OR EDUCATION } \\
\text { SCIENTIFIC DISCIPLINES ) AND DOCUMENT } \\
\text { TYPES: (PROCEEDINGS PAPER ) AND } \\
\text { RESEARCH AREAS: (SOCIAL SCIENCES } \\
\text { OTHER TOPICS OR EDUCATION } \\
\text { EDUCATIONAL RESEARCH OR SCIENCE } \\
\text { TECHNOLOGY OTHER TOPICS OR } \\
\text { COMPUTER SCIENCE ) } \\
\text { Indexes=SCI-EXPANDED, SSCI, CPCI-S, } \\
\text { CPCI-SSH Timespan=2016-2019 }\end{array}$ \\
\hline $\begin{array}{l}\text { ACM } \\
\text { Library }\end{array}$ & $\begin{array}{l}\text { "query" : }\{\text { (+risk +prediction +network campus } \\
\text { university education) \} } \\
\text { "filter" : }\{\text { "publicationYear": }\{\text { "gte":2016 \}\}, } \\
\text { \{owners.owner=HOSTED\} }\end{array}$ \\
\hline Scopus & $\begin{array}{l}\text { ( TITLE-ABS-KEY ( risk ) AND } \\
\text { TITLE-ABS-KEY ( prediction) OR } \\
\text { TITLE-ABS-KEY ( education) OR } \\
\text { TITLE-ABS-KEY ( university ) OR } \\
\text { TITLE-ABS-KEY ( campus) AND } \\
\text { TITLE-ABS-KEY ( network)) AND PUBYEAR > } \\
2015 \text { AND ( LIMIT-TO ( SUBJAREA, "COMP") } \\
\text { OR LIMIT-TO ( SUBJAREA, "SOCI" ) ) AND } \\
\text { ( EXCLUDE ( EXACTKEYWORD, "Forecasting" ) } \\
\text { OR EXCLUDE (EXACTKEYWORD, "Human" ) } \\
\text { OR EXCLUDE (EXACTKEYWORD, "Humans" ) ) } \\
\text { AND (LIMIT-TO ( SUBJAREA, "DECI" ) ) }\end{array}$ \\
\hline IEEE Xplore & $\begin{array}{l}\quad \text { (((((risk) AND prediction) OR campus) OR } \\
\text { university) OR education) AND network) } \\
\text { Filters Applied: IEEE Conferences Journals Early } \\
\text { Access Articles IEEE Transactions on Neural } \\
\text { Networks and Learning Systems } 2018 \text { International } \\
\text { Joint Conference on Neural Networks (IJCNN) } \\
\text { learning (artificial intelligence) neural nets pattern } \\
\text { classification regression analysis support vector } \\
\text { machines 2016 - } 2020\end{array}$ \\
\hline SpringerLink & $\begin{array}{l}\text { 'risk AND prediction AND network AND (campus } \\
\text { OR university OR education)' } \\
\text { within Computer Science, Artificial Intelligence (incl. } \\
\text { Robotics), Database Management, Information } \\
\text { Systems Applications (incl. Internet), Data Mining and } \\
\text { Knowledge Discovery, } 2016 \text { - } 2019\end{array}$ \\
\hline
\end{tabular}

The articles are summarized in Table II tabulate data mining technique, prediction scope and dataset that researchers used in their research study. In comprehensive literature search that we have conducted, most of the research paper looked at student performance prediction, education management risk prediction, software prediction, predicting academic dropout and predicting academic performance. There are few studies on risk prediction in university network look at cybersecurity threats.
Table 2: Data Mining Techniques and Prediction Area in University Environment

\begin{tabular}{|c|c|c|c|}
\hline $\begin{array}{l}\text { PAPER } \\
\text { ID }\end{array}$ & $\begin{array}{c}\text { DATA MINING } \\
\text { /OTHER } \\
\text { TECHNIQUE }\end{array}$ & $\begin{array}{c}\text { PREDICTION } \\
\text { AREA }\end{array}$ & DATASET \\
\hline $1[27]$ & Neural Network & Dropout Student & $\begin{array}{l}2670 \text { students } \\
\text { enrolled in } \\
\text { undergraduate } \\
\text { studies }\end{array}$ \\
\hline $2[28]$ & $\begin{array}{l}\text { Proposed EDADT } \\
\text { Algorithm }\end{array}$ & $\begin{array}{l}\text { Intrusion Detection } \\
\text { System }\end{array}$ & KDD Cup dataset \\
\hline 3 [29] & Fuzzy Logic & $\begin{array}{l}\text { Telecommunicatio } \\
\text { n Network }\end{array}$ & $\begin{array}{l}\text { Questionnaires } \\
\text { from Expert } \\
\text { Judgments }\end{array}$ \\
\hline $4[30]$ & $\begin{array}{l}\text { Grey Relation } \\
\text { Coefficient Matrix }\end{array}$ & Network Risk & $\begin{array}{l}\text { Questionnaires } \\
\text { from Expert Group }\end{array}$ \\
\hline $5[31]$ & $\begin{array}{l}\text { Threat Driven } \\
\text { Modelling }\end{array}$ & $\begin{array}{l}\text { Software } \\
\text { Development and } \\
\text { Business } \\
\text { Infrastructure }\end{array}$ & $\begin{array}{l}\text { Capture from } \\
\text { Packet Analyser }\end{array}$ \\
\hline $6[32]$ & $\begin{array}{l}\text { Risk management } \\
\text { processes }\end{array}$ & $\begin{array}{l}\text { Literature from all } \\
\text { Malaysia university } \\
\text { perspective }\end{array}$ & $\begin{array}{l}\text { University } \\
\text { Transformation } \\
\text { Program (UTP) } \\
\text { Green Book } \\
\end{array}$ \\
\hline 7 [33] & $\begin{array}{l}\text { Hidden Markov } \\
\text { Model }\end{array}$ & Risk Assessment & $\begin{array}{l}\text { Capture from Snort } \\
\text { IDS }\end{array}$ \\
\hline $8[34]$ & ANOVA Test & $\begin{array}{l}\text { Unauthorized and } \\
\text { Suspicious Traffic }\end{array}$ & Firewall Logs \\
\hline 9 [35] & $\begin{array}{l}\text { Quantitative } \\
\text { Information } \\
\text { Security Risk } \\
\text { Assessment } \\
\text { OCTAVE } \\
\end{array}$ & $\begin{array}{l}\text { Information Risk } \\
\text { Assessment }\end{array}$ & $\begin{array}{l}\text { Network } \\
\text { Environment of } \\
\text { University Campus }\end{array}$ \\
\hline $10[5]$ & Literature Study & Threat Assessment & $\begin{array}{l}\text { Communications } \\
\text { with University's } \\
\text { Members }\end{array}$ \\
\hline $11[36]$ & $\begin{array}{l}\text { Adopting the Best } \\
\text { Practices, don't } \\
\text { have any } \\
\text { recommendation } \\
\text { for the Best } \\
\text { Practice }\end{array}$ & $\begin{array}{l}\text { Information } \\
\text { Security } \\
\text { Management } \\
\text { System (ISMS) }\end{array}$ & Review paper \\
\hline $12[37]$ & $\begin{array}{l}\text { Random Forest } \\
\text { Classifier \& } \\
\text { Semi-Supervised } \\
\text { Learning } \\
\end{array}$ & Infected Machines & Binary File Logs \\
\hline $13[38]$ & $\begin{array}{l}\text { Fuzzy Cognitive } \\
\text { Maps }\end{array}$ & risk assessment & $\begin{array}{l}\text { Log Files of the } \\
\text { Network } \\
\text { Infrastructure }\end{array}$ \\
\hline $14[39]$ & $\begin{array}{l}\text { Scientific } \\
\text { Decision-Making }\end{array}$ & $\begin{array}{l}\text { Security Strategy of } \\
\text { Campus Network }\end{array}$ & $\begin{array}{l}\text { College Computer } \\
\text { Network }\end{array}$ \\
\hline $15[13]$ & $\begin{array}{l}\text { Risk Assessment } \\
\text { Model }\end{array}$ & Security Breach & $\begin{array}{l}\text { University Campus } \\
\text { Network }\end{array}$ \\
\hline
\end{tabular}

A study from [40] stated that data analytics can be categorize to three group which are industry and business, scientific research and urban planning. As in this research, we as researcher apply data sciences approach to help industry and business in making their decision and also proposed a model for scientific research for university campus network in doing risk assessment.

\section{CONCLUSION}

This paper is focusing on reviewing how risk prediction technique is implemented in university network and how data mining algorithm have been used to other researchers. From comprehensive literature search from top 5 computer science 
research databases, there are lack of study looking at risk prediction in university network. There is also a gap from past research measured at cybersecurity threats. Past research not much cover on cybersecurity threats in campus network and aiming a risk prediction technique in getting a reliable risk assessment result. There are also lacking experiment using firewall dataset in campus network which by using this data will help in doing risk assessment in order to have more reliable prediction on campus network risk. The result from comprehensive literature search that we have conducted show that most of the research paper looked at student performance prediction, education management risk prediction, software prediction, predicting academic dropout and predicting academic performance. There are few studies on risk prediction on university network look at cybersecurity threats.

\section{REFERENCES}

1. Editorial Staff, Protecting Critical Infrastructure - Understanding the Threat to SCADA Networks. pp. 7-9, 2014.

2. M. Hamdi, M. Safran, and W. C. Hou, A Security Novel For A Networked Database, Proc. - 2014 Int. Conf. Comput. Sci. Comput. Intell. CSCI 2014, vol. 1, pp. 279-284, 2014.

https://doi.org/10.1109/CSCI.2014.55

3. N. Feng and M. Li, An Information Systems Security Risk Assessment Model Under Uncertain Environment, Appl. Soft Comput., vol. 11, no. 7, pp. 4332-4340, 2011.

4. I. Anikin and L. Y. Emaletdinova, Information Security Risk Management In Computer Networks Based On Fuzzy Logic And Cost/Benefit Ratio Estimation, in Proceedings of the 8th International Conference on Security of Information and Networks - SIN '15, 2015, pp. 8-11.

5. C. Regehr, G. D. Glancy, A. Carter, and L. Ramshaw, A Comprehensive Approach To Managing Threats Of Violence On A University Or College Campus, Int. J. Law Psychiatry, vol. 54, pp. 140-147, 2017.

https://doi.org/10.1016/j.ijlp.2017.06.009

6. U.S. Department of Education, Data Security : Top Threats to Data Protection, 2011.

7. A. Ekelhart, S. Fenz, and T. Neubauer, AURUM : A Framework for Information Security Risk Management, Sci. York, vol. 0, no. September 2008, pp. 1-10, 2009.

8. P. Pandey and E. A. Snekkenes, Applicability of Prediction Markets in Information Security Risk Management, 2014 25th Int. Work. Database Expert Syst. Appl., pp. 296-300, 2014.

9. A. Connell and T. Waits, The CERT Assessment Tool: Increasing A Security Incident Responder's Ability To Assess Risk, in 2013 IEEE International Conference on Technologies for Homeland Security, HST 2013, 2013, pp. 236-240.
https://doi.org/10.1109/THS.2013.6699006

10. Y. Sun, Research on the Defects and Improvement of Internal Control of Scientific Research Funds in Colleges and Universities Based on FMEA Model, in 2017 International Conference on Service Systems and Service Management, 2017.

11. Y. Jia, H. Wu, and D. Jiang, A Hierarchical Framework of Security Situation Assessment for Information System, 2015 Int. Conf. Cyber-Enabled Distrib. Comput. Knowl. Discov., pp. 23-28, 2015.

12. A. Adamov, M. Erguvan, and S. Durmaz, Towards Good Governance through Implementation of University Management Information System: Qafqaz University's Experience, in The 4th International Conference on Application of Information and Communication Technologies, 2010, pp. 1-7.

13. C. Joshi and U. K. Singh, Information Security Risks Management Framework - A Step Towards Mitigating Security Risks In University Network, J. Inf. Secur. Appl., vol. 35, pp. 128-137, 2017.

14. M. J. Christ, R. N. P. Tri, W. Chandra, and T. Mauritsius, Lending Club Default Prediction using Naïve Bayes and Decision Tree, Int. J. Adv. Trends Comput. Sci. Eng., vol. 8, no. 5, pp. 2528-2534, 2019.

https://doi.org/10.30534/ijatcse/2019/99852019

15. Q. Yu, Y. Shen, and A. Grey, Research of Information Security Risk Prediction based on Grey Theory and ANP, 2016 IEEE Adv. Inf. Manag. Commun. Electron. Autom. Control Conf., no. x, pp. 107-113, 2016.

16. H. Mohammed, I. A. Hameed, and R. Seidu, Adaptive Neuro-Fuzzy Inference System for Predicting Norovirus in Drinking Water Supply, in International Conference on Informatics, Health \& Technology (ICIHT), 2017, pp. 1-6.

17. S. Banu and S. Swamy, Prediction of Heart Disease at early stage using Data Mining and Big Data Analytics: A Survey, in International Conference on Electrical, Electronics, Communication, Computer and Optimization Techniques, 2016, pp. 256-261.

18. R. D. Peng and E. Matsui, The Art of Data Science A Guide for Anyone Who Works with Data. Lean Publishing, 2016.

19. N. Paltrinieri, L. Comfort, and G. Reniers, Learning About Risk: Machine Learning For Risk Assessment, Saf. Sci., vol. 118, no. June, pp. 475-486, 2019. https://doi.org/10.1016/j.ssci.2019.06.001

20. B. Srinivasan and K. Pavya, A Study On Data Mining Prediction Techniques In Healthcare Sector, pp. 552-556, 2016. 
21. W. Muhamad, T. Wan, N. Laila, A. Ghani, and S. M. Drus, Data Mining Techniques for Disease Risk Prediction Model : A Systematic Literature Review, in Proceedings of the 3rd International Conference of Reliable Information and Communication Technology (IRICT 2018), 2019, no. January, pp. 40-46.

22. R. Shroff, Predictive Analytics for City Agencies : Lessons from Children's Services, vol. 5, no. 3, pp. 189-196, 2017.

23. G. Giannopoulos, R. Filippini, and M. Schimmer, Risk Assessment Methodologies For Critical Infrastructure Protection. Part I: A State Of The Art., European Commission JRC (Joint Research Center) Technical notes. p. 53, 2012.

24. T. Ahmed, T. Calders, H. Lu, and T. B. Pedersen, Risk Detection and Prediction from Indoor Tracking Data, pp. 11-18, 2014. https://doi.org/10.1145/3151123.3151126

25. G. Stergiopoulos, P. Kotzanikolaou, M. Theocharidou, and D. Gritzalis, Risk Mitigation Strategies For Critical Infrastructures Based On Graph Centrality Analysis, Int. J. Crit. Infrastruct. Prot., vol. 10, no. August, pp. 34-44, 2015.

26. K. Hajdarevic, C. Pattinson, K. Kozaric, and A. Hadzic, Information Security Measurement Infrastructure for KPI Visualization, pp. 1543-1548, 2012.

27. M. Alban and D. Mauricio, Neural Networks to Predict Dropout at the Universities, vol. 9, no. 2, pp. 9-13, 2019.

28. G. V Nadiammai and M. Hemalatha, Effective Approach Toward Intrusion Detection System Using Data Mining Techniques, Egypt. Informatics J., vol. 15, no. 1, pp. 37-50, 2014.

29. I. V Anikin, Information Security Risks Assessment in Telecommunication Network of the University, no. 1.

30. M. Li, W. Li, X. Zeng, P. Yu, and X. Qiu, A Decision-Making Mechanism of Network Risk Control Based on Grey Relation, NOMS 2018 2018 IEEE/IFIP Netw. Oper. Manag. Symp., pp. $1-4,2018$.

31. M. A. Naagas and T. D. Palaoag, A Threat-Driven Approach to Modeling a Campus Network Security, in International Conference on Communications and Broadband Networking, 2018, pp. 1-7.

https://doi.org/10.1145/3193092.3193096

32. R. Md.Sum and Z. M. Saad, Risk Management in Universities, in 3rd International Conference on Qalb-Guided Leadership in Higher Education Institutions, 2017, no. December, pp. 128-142.

33. Q. Zhang et al., SVAPP Methodology: A Predictive Security Vulnerability Assessment Modelling Method, J. Loss Prev. Process Ind., vol. 2, no. December, pp. 15-28, 2016.
34. J. Week and S. Week, A Firewall Data Log Analysis of Unauthorized and Suspicious Traffic, no. January 2011, 2015.

35. C. Joshi, Quantitative Information Security Risk Assessment Model for University Computing Environment, in International Conference on Information Technology, 2016, pp. 69-74.

36. H. Rehman, A. Masood, and A. R. Cheema, Information Security Management in Academic Institutes of Pakistan, pp. 47-51, 2013.

37. L. Bilge, Y. Han, and M. Dell 'Amico, RiskTeller: Predicting the Risk of Cyber Incidents, $A C M$ Conf. Comput. Commun. Secur., no. 1, pp. 1299-1311, 2017.

38. R. Sarala, G. Zayaraz, and V. Vijayalakshmi, Fuzzy Cognitive Map-Based Reasoning For Prediction Of Multi-Stage Attacks In Risk Assessment, Interdiscip. J. Intell. Eng. Informatics, vol. 4, no. 2, 2016.

39. J. Wang and X. Liu, Computer Network Security of University And Preventive Strategy, IEEE 3rd Int. Conf. Commun. Softw. Networks, pp. 143-145, 2011.

40. S. B. Lim, Classification and Big Data Usages for Industrial Applications, Int. J. Adv. Trends Comput. Sci. Eng., vol. 8, no. 4, pp. 1-6, 2019. https://doi.org/10.30534/ijatcse/2019/18842019 